$\mathbb{T}$ periodica polytechnica

\author{
Transportation Engineering \\ $39 / 2(2011) 63 \quad 68$ \\ doi: 10.3311/pp.tr.2011-2.03 \\ web: http://www.pp.bme.hu/tr \\ (c) Periodica Polytechnica 2011
}

RESEARCH ARTICLE

\section{Data envelopment analysis and its key variants utilized in the transport sector}

\author{
Rita Markovits-Somogyi
}

Received 2010-09-07

\begin{abstract}
Having reviewed the international literature on data envelopment analysis (DEA), a non-parametric linear programming method used for efficiency evaluation, the aim of the author with the present article was to fill a gap by collecting and summarizing the essence of the main variants of DEA applied in the transport sector. Thus the DEA CCR, BCC and the Simar-Wilson method are presented. DEA CCR enables the efficiency evaluation under constant, DEA BCC under variable returns to scale. The Simar-Wilson method, also referred to as the truncated bootstrap method, is currently seen as the most reliable technique for hypothesis testing and confidence interval estimation under DEA. Some extensions, like the super-efficient DEA, the principal component analysis and the MNDEA are also highlighted. The variants included in the article were selected on the basis of their application in the transport sector, of which examples are also provided.
\end{abstract}

\author{
Keywords \\ DEA $\cdot$ efficiency $\cdot C C R \cdot B C C \cdot$ Simar-Wilson method
}

Rita Markovits-Somogyi

Department of Transport Economics, BME, H-1111 Budapest Bertalan L. u. 2, Hungary

e-mail: rsomogyi@kgazd.bme.hu

\section{Introduction}

Data Envelopment Analysis (DEA) is a non-parametric linear programming method used to determine the efficiency of a set of companies as compared to a best practice frontier and was introduced by Farrel [15] and Charnes, Cooper, Rhodes [11] in the middle of the last century. Since its creation, it has been applied for the evaluation of a multitude of decision making units (DMUs) in various fields, e.g. in the agriculture, in the bank sector and in the health industry as well. As it can measure the efficiency of multiple input - multiple output production units, it has also been widely employed in the transport sector, especially for the evaluation of airport, ports, railways and public transport companies. In Hungary it is not very widespread though: there are only two studies known to apply the method in the upper education and in the agriculture, respectively [26] and [10]. It shall, however, be mentioned that some other related methods like cost and performance management models have already been discussed by Hungarian researchers [9].

Since its introduction, DEA has seen many variants, depending on the intention of the authors and on external conditions, like the quantity and quality of available data on inputs and outputs. This article strives to present the essence of the most important variants of DEA applied in the transport sector, with special emphasis on the most fundamental methods, CCR and BCC, and the Simar-Wilson method, which is currently the most reliable extension of the original technique and is being employed by more and more authors. Finally, some extensions of DEA, like the super-efficiency method, the principal component analysis and the MNDEA are also highlighted, all of them with examples of application in the transport sector.

\section{The basic method: DEA CCR}

The basic idea behind the DEA efficiency estimator is the ratio of outputs to inputs. A company is more efficient, if it can produce a larger number of outputs with the same quantity of inputs (output oriented approach), or else, if it can produce the same amount of outputs with a smaller quantity of inputs (input oriented approach). With this ratio in mind, the efficiency of the observed DMUs can be evaluated by forming a best prac- 
tice frontier as based on the performance of the best achieving companies and comparing the rest to them. This leads us to the most basic DEA method, the CCR (named after the initial of the authors, Charnes, Cooper, Rhodes in [11], the most vital characteristic of which is that it deals with constant returns to scale. This means that the DMUs investigated operate at the most efficient scale size.

The idea presented in the previous paragraph can mathematically be described as follows ([13], [19]): let us assume that there are $n$ DMUs to be evaluated. Each DMU consumes $m$ different inputs, and produces $s$ different outputs. Thus e.g. $\mathrm{DMU}_{j}$ consumes $\mathrm{x}_{i j}$ of input $\mathrm{i}$, and produces $\mathrm{y}_{r j}$ of output $\mathrm{r}$. We also assume that $\mathrm{x}_{i j} \geq 0, \mathrm{y}_{r j} \quad \geq 0$ and for each DMU there is at least one positive input and one positive output.

From these the ratio of outputs to inputs is used to measure the relative efficiency $\mathrm{DMU}_{j}=\mathrm{DMU}_{0}$, the $\mathrm{DMU}$ to be evaluated relative to the ratio of all the $\mathrm{j}=1,2, \ldots, \mathrm{n} \mathrm{DMU}_{j} \mathrm{~s}$.

Thus the function to be maximised is:

$$
\max h_{0}(u, v)=\frac{\sum_{r=1}^{s} u_{r} y_{r} 0}{\sum_{i=1}^{m} v_{i} x_{i 0}}
$$

where $\mathrm{u}_{r}, \mathrm{v}_{i}$ are weights,

$\mathrm{y}_{r 0}, \mathrm{x}_{i 0}$ are the observed input/output values of $\mathrm{DMU}_{0}$ (the DMU to be evaluated). We introduce the following constraints so as to give a limit to the values:

$$
\frac{\sum_{r=1}^{s} u_{r} y_{r j}}{\sum_{i=1}^{m} v_{i} x_{i j}} \leq 1
$$

for $i=1,2, \ldots, n$ and $u_{r}, v_{i} \geq 0$.

Using the Charnes-Cooper transformation this leads us to the following equivalent linear programming problem:

$$
\max z=\sum_{r=1}^{s} \mu_{r} y_{r} 0
$$

subject to

$$
\begin{aligned}
\sum_{r=1}^{s} \mu_{r} y_{r j}-\sum_{i=1}^{m} v_{i} x_{i j} & \leq 0 \\
\sum_{i=1}^{m} v_{i} x_{i 0} & =1 \\
\mu_{r}, v_{i} & \geq 0
\end{aligned}
$$

where $(u, v)$ change to $(\mu, v)$ as a result of the Charnes-Cooper transformation. By virtue of the duality theorem in LP (where $z^{*}=\theta *$, (3) can be transformed into:

$$
\theta^{\bullet}=\min \theta
$$

subject to

$$
\begin{array}{rl}
\sum_{j=1}^{n} x_{i, j} \lambda_{j} \leq \theta x_{i 0} & i=1,2, \ldots, m \\
\sum_{j=1}^{n} y_{r, j} \lambda_{j} \geq y_{r 0} & r=1,2, \ldots, s \\
\lambda_{j} \geq 0 & j=1,2, \ldots, n
\end{array}
$$

(4) is called the "strong disposal" or "weak efficiency" model, as it ignores non-zero slacks. Should we want to take them also into account, we have to use the following modified model, also called the envelopment model:

$$
\min \theta-\varepsilon\left(\sum_{i=1}^{m} s_{i}^{-}+\sum_{r=1}^{s} s_{r}^{+}\right)
$$

subject to

$$
\begin{array}{rc}
\sum_{j=1}^{n} x_{i j} \lambda_{j}+s_{i}^{-}=\theta x_{i 0} & i=1,2, \ldots, m \\
\sum_{j=1}^{n} y_{r j} \lambda_{j}-s_{r}^{+}=y_{r 0} & r=1,2, \ldots, s \\
\lambda_{j}, s_{i}^{-}, s_{r}^{+} \geq 0 & \forall i, j, r
\end{array}
$$

where $\varepsilon$ is a non-Archimedean element, defined to be smaller than any positive real number.

Using these formulae a $\mathrm{DMU}_{0}$ is efficient if and only if $\theta^{*}=$ 1 and $\mathrm{s}_{i}^{-*}=\mathrm{s}_{r}^{+*}=0$ for all i,r, and it is weakly efficient, if $\theta^{*}=1$, and $\mathrm{s}_{i}^{-*} \neq 0$ and/or $\mathrm{s}_{r}^{+*} \neq 0$ for some $\mathrm{i}$ and $\mathrm{r}$ in some alternate optima [13]. Formula (5) represents the input-oriented DEA CCR model (envelopment form). The output oriented model is also very similar with the difference in the values to be maximized/minimized.

\section{The BCC model}

The DEA BCC (named after Banker, Charnes and Cooper in [4]) model incorporates an additional constraint, the convexity constraint:

$$
\sum_{j=1}^{n} \lambda_{j}=1
$$

which enables to take into account the non-constant returns to scale. Undoubtedly, in most of the cases the possibility of variable returns to scale has to be considered. That is why several studies employ both techniques at the same time, and if the efficiency values do not match, there is scale inefficiency and the companies at hand display variable returns to scale. In these cases the original DEA CCR value can be decomposed into scale inefficiency and "pure technical inefficiency" [12]. Table 1 shows a selection of studies which apply CCR, BCC or both of the methods in the transport sector. 
Tab. 1. Studies applying the CCR and/or the BCC DEA method

\begin{tabular}{llll}
\hline Source & CCR & BCC & Transport mode \\
\hline Adler and Berechman, 2001 & & $\checkmark$ & airports \\
1]. & & & \\
Barros and Dieke, 2008 [7] & $\checkmark$ & $\checkmark$ & airports \\
Barros, 2008. [5] & $\checkmark$ & $\checkmark$ & airports \\
Cullinane and Wang, 2005. & $\checkmark$ & $\checkmark$ & ports \\
14] & & & \\
Jitsuzumi and Nakamura, & & $\checkmark$ & railways \\
2010. 18, & & & \\
Martin and Roman, 2001. 20] & $\checkmark$ & $\checkmark$ & airports \\
Pacheco and Fernandes, & & $\checkmark$ & airports \\
2003. 22. & & & \\
Pina and Torres, 2001. 23] & & $\checkmark$ & urban public transport \\
Sampaio et al., 2008. [24] & & $\checkmark$ & public transport \\
Wu and Goh, 2010. 27. & $\checkmark$ & $\checkmark$ & ports \\
Yoshida and Fujimoto, 2004. & $\checkmark$ & $\checkmark$ & airports \\
28, & & & \\
\hline
\end{tabular}

[source: own research]

\section{The Simar-Wilson method}

L. Simar and P.W. Wilson have realised that there is an aspect of DEA that can be and also needs to be improved. They point to the nature of the efficiency value determined by the DEA method: in many studies the authors do not take into account that it is not the result of a deterministic process and the outcome of the calculations relies on the data observed, i.e. the composition of the dataset [13]. That is why Simar and Wilson have developed the truncated bootstrap method (also referred to as the Simar-Wilson approach), which enables the researchers to calculate a confidence interval along with their results, and the efficiency values can also be corrected. An intermediate step in the algorithm enables hypothesis testing later on as well.

It has to be noted that their approach is not the mere application of the bootstrap known in statistics (to which Simar and Wilson refer to as naive bootstrap), since unlike in the linear regression model, the data generating process, $F$, has bounded support over $P$, and also the conditional density $f(D(x, y \mid P) \quad \mid x, \eta)$ has bounded support over the interval $(0,1)$, and is right-discontinuous at 1 .

$F$ the data generating process (DGP), $F=F(P, f(x, y))$,

$P \quad$ production set, where $P \equiv\{(x, y) \mid x$ can produce $\mathrm{y}\}$,

$x$ denotes a vector of $p$ inputs,

$y$ denotes a vector of $q$ outputs,

$\eta \quad$ cylindrical coordinate of the probability density function,

$D$ is the output distance function, $D(x, y \mid P)$.

These constraints cause the naive bootstrap to give inconsistent estimates. That is why Simar and Wilson have developed their method which can be summarised as follows [13]:

1 Let us calculate the "traditional" DEA efficiency $(D)$, utiliz- ing e.g. the BCC method.

$$
D\left(x_{i}, y_{i} \mid \hat{P}\right) \quad i=1 \ldots n
$$

$i$ the number of DMUs

$\hat{P}$ refers to the production set and the application of the BCC method.

2 If the $\mathrm{DMU}_{0}$ has not been part of the set involved in the calculation $\left(S_{n}\right)$, calculate the efficiency for $\mathrm{DMU}_{0}$ as well:

$$
D\left(x_{0}, y_{0} \mid \hat{P}\right) \quad i=1 \ldots n
$$

3 Reflect the efficiency values about unity, and determine the bandwidth parameter $h$ needed in the next step for kernel density estimation. The reflection is necessary so as to enable us to apply a (kernel) density function.

4 Applying the rules of bootstrapping and the kernel density function with bandwidth value $\mathrm{h}$, determine new efficiency values $\left(D_{i}^{*}\right)$.

5 Create a new dataset as based on the efficiency values of step 4.

$$
y_{i}^{*}=\frac{D_{i}^{*} y_{i}}{D\left(x_{i}, y_{i} \mid \hat{P}\right)} ; \quad x_{i}^{*}=x
$$

6 Give a new efficiency estimate, as based on the new dataset $\left(\hat{P}^{*}\right)$ created in step 5:

$$
D^{*}\left(x_{0}, y_{0} \mid \hat{P}^{*}\right)
$$

Thus the previous steps have yielded a single efficiency estimate relative to $\mathrm{DMU}_{0}$, on the basis of the new dataset created with the bootstrapping method using a kernel density function.

7 Repeat steps 4-6 $B$ times. This results in $B$ number of efficiency estimates relative to $\mathrm{DMU}_{0}$, as based on $B$ different datasets.

8 Determine the confidence interval $\left(\mathrm{I}_{a}\right)$. For this, calculate $\hat{a}_{\alpha}$ and $\hat{b}_{\alpha}$ from

$$
\begin{aligned}
& \operatorname{Pr}\left(-\hat{b}_{\alpha} \leq D\left(x_{0}, y_{0} \mid \hat{P}^{*}\right)-D\left(x_{0}, y_{0} \mid \hat{P}\right) \leq-\hat{a}_{\alpha} \mid \hat{F}\left(S_{n}\right)\right) \\
& \approx 1-\alpha \\
& \text { where } \\
& \operatorname{Pr} \quad \text { stands for probability, } \\
& 1-\alpha \quad \text { the required significance level, } \\
& S_{n} \quad \text { the set of the observed data. }
\end{aligned}
$$

Values $\hat{a}_{\alpha}$ and $\hat{b}_{\alpha}$ can be found via sorting the values

$$
D\left(x_{0}, y_{0} \mid \hat{P}^{*}\right)-D\left(x_{0}, y_{0} \mid \hat{P}\right) \quad b=1 \ldots B
$$

in an increasing order and then deleting $\left(\frac{\alpha}{2} \cdot 100\right)$-percent of the elements at both ends of the list (hence the name "truncated" bootstrap), and then setting $-\hat{a}_{\alpha}$ and $-\hat{b}_{\alpha}$ equal to the 
endpoints of the truncated, sorted array, with $\hat{a}_{\alpha} \leq \hat{b}_{\alpha}$. Then the (1- $\alpha)$-percent confidence interval is:

$$
D\left(x_{0}, y_{0} \mid \hat{P}\right)+\hat{a}_{\alpha} \leq D\left(x_{0}, y_{0} \mid P\right) \leq D\left(x_{0}, y_{0} \mid \hat{P}\right)+\hat{b}_{\alpha}
$$

Finally, the bias-corrected estimator can be calculated in the following way:

$$
\hat{\hat{D}}\left(x_{0}, y_{0}\right)=2 D\left(x_{0}, y_{0} \mid \hat{P}\right)-B^{-1} \sum_{b=1}^{B} D_{b}\left(x_{0}, y_{0} \mid \hat{P}^{*}\right)
$$

Should we be interested in the confidence intervals for all the efficiency estimates of all the DMUs observed, then we can obviously omit step 2 , and it is computationally more cost-effective to incorporate step 7 into step 6, i.e. calculating the "new" efficiency estimates $\left(D^{*}\left(x_{i}, y_{i} q m i d \hat{P}^{*}\right)\right)$ in each bootstrapping loop for each DMU, $\mathrm{i}=1$...n.

The process presented above can be further improved by using an iterative approach in which a second-level bootstrap sample $\left(S_{n}^{* *}\right)$ is generated from $S_{n}^{*}$ in the same way as $S_{n}^{*}$ was created from $S_{n}$. Using $S_{n}^{* *}$, a new confidence interval is determined (by calculating the values $\hat{a}_{a}^{*}, \hat{b}_{a}^{*}$ ), and by repeating the first-level bootstrap many times, the proportion of times can be established when $D\left(x_{0}, y_{0} \mid \hat{P}\right)$ is in this new confidence interval. The resulting value $(\hat{\pi}(\alpha))$ can be used to estimate how many times the original efficiency value is covered by the initial confidence interval, $\mathrm{I}_{a}$. We can search for a solution $\hat{\alpha}$ in the equation:

$$
\hat{\pi}(\hat{\alpha})=1-\alpha_{0}
$$

and create with this value the final, corrected confidence interval, $I_{\hat{\alpha}}$.

The truncated bootstrap method has been used for different purposes in the literature. Obviously, it is excellent (and in the present regarded as the only valid method) for the determination of the confidence intervals and the bias-corrected efficiency estimates. Hung et al. [17] for instance evaluate the efficiency of 31 Asian container ports with the DEA method, and correct for bias inherent in the method and provide confidence intervals for the estimated efficiency values with the Simar-Wilson technique. It is worth noting that some ports which were ranked as efficient in the first stage of the process (i.e. efficiency value $=1$ ), proved to be much less efficient when applying the bootstrap method, while some ports gained a higher ranking in the second stage of the process. The authors do not offer an explanation of the phenomenon but the differences might be attributed to the fact that the efficiency scores are biased in the first stage DEA, as there might be some production feasibilities that are possible but are not included in the sample [7].

Surprisingly, this use of the Simar-Wilson method cannot be found in many studies yet. Most of the authors who employ the technique, rather apply it for testing the parameters influencing efficiency. Such statistical inference can be found in [7] which examines the efficiency of 31 Italian airports over a time frame of three years and uses the following equation to describe the components of efficiency:

$$
T \hat{E}_{i} \approx a+Z_{i} \delta+\varepsilon_{i} \quad j=1 \ldots n
$$

where

$$
\begin{array}{ll}
T E_{i} & \text { technical efficiency of the } i \text { th firm, } \\
a & \text { constant term, } \\
Z_{i} & \begin{array}{l}
\text { row vector of observed specific variables for } \\
\mathrm{DMU}_{j},
\end{array} \\
\delta & \text { weights, } \\
\varepsilon_{i} & \text { statistical noise, and where } \varepsilon_{j} \geq 1-a-Z_{j} \delta .
\end{array}
$$

Form (15) is then rewritten as:

$$
\begin{array}{r}
\theta_{i, t}=\beta_{0}+\beta_{1} \text { trend }_{i, t}+\beta_{2} \text { hubs }_{i, t}+ \\
+\beta_{3} W L U_{i, t}+\beta_{4} \text { private }_{i, t}+\beta_{5} \text { North }_{i, t}+\varepsilon_{i, t}
\end{array}
$$

$\theta_{i, t} \quad$ efficiency of $\mathrm{DMU}_{i}$ in time period $t$,

$\beta_{0} \quad$ constant term,

$\beta_{j}, \quad \mathrm{j}=1, . ., 5$, weights,

trend the yearly trend,

WLU dummy variable, showing whether the airport is a regional hub,

private dummy variable, showing whether the airport is a private firm,

North dummy variable, showing whether it can be found in the North of the country.

Very similar functional form can be found in [5] where again the Simar-Wilson technique is utilized alongside with DEA for the efficiency evaluation of 32 Argentinean airports, and in [6], which investigates 27 European airlines.

The same approach is also taken by Odeck [21], who examines 18 Norwegian road toll companies and uses the truncated bootstrap method to investigate the influence of different exogenous parameters (the age of the toll company, the share of automatic vehicle identification, presence of passenger payment, number of lanes) on efficiency.

Finally, a very interesting application of the truncated bootstrap method can be found in [16] which examines the efficiency of 179 German public transport companies. As based on previous work of Simar and Wilson [25] the authors point out that if the ratio of CRS and VRS efficiency values is not unity then one cannot determine whether the difference is the result of a non-CRS efficiency, or it is simply caused by sampling variation. Thus after carrying out a traditional DEA analysis, the authors employ the Simar-Wilson method to determine the returns to scale of the decision making units. The robustness of the results is also tested.

\section{Some extensions to DEA}

\subsection{The super-efficient DEA}

Traditional DEA does not fully rank the DMUs, that is, there is no order provided between the efficient companies (since all 
receive an efficiency value of one). There are some cases, however, when such a rank would be desirable. That is why Andersen and Petersen [3] have developed the super-efficient DEA method (also called A\&P method). In this the best practice frontier is created first without evaluating $\mathrm{DMU}_{0}$, and then with its inclusion, the extent to which the envelopment frontier becomes extended is investigated. Thus $\mathrm{DMU}_{0}$ can even be attributed an efficiency value higher than unity.

An advantage of this method is that no a priori information is needed to create a full rank of the DMUs. Adler and Berechman [1] evaluate 26 airports of Western Europe, North America, and the Far East with the super-efficient DEA method, Bazargan and Vasigh [8] apply super-efficiency for the ranking of 45 US airports, Hirshhausen and Cullmann [16] treat the problem of outliers with this method in their study, while $\mathrm{Wu}$ and Goh [27] utilize the method to investigate the efficiency of 21 container ports.

\subsection{Principal component analysis}

Another, recurrent problem inherent in DEA is the limited number of inputs and outputs. As the best practice frontier is created on the basis of the observed data, the greater the number of inputs and outputs, the more DMUs are deemed to be efficient. Thus, as a thumb rule, the number of observations should be three times greater than the number of the inputs plus outputs; and the number of DMUs should be equal or larger than the product of the number of inputs and outputs. But sometimes this constraint can not be adhered to as the researchers wish to include a larger number of inputs and outputs.

The resulting problem can be overcome by principal component analysis (PCA) which describes data through a reduced number of variables. These principal components are created through linear combination of the variables and they generally describe $80-90 \%$ of the variance in the data, so they can be used instead of the original variables, in our case, the inputs and outputs [1]. PCA can be combined with DEA as introduced in the work of Adler and Golany [2]. Adler and Berechman [1] use this technique to reduce the 5 observed output variables to 3 principal components in their analysis related to the efficiency of airports.

\subsection{MNDEA}

Transport has some specific features which distinguish it from other types of production or service processes. One of these is its "unstorability". This characteristic is a factor that should be taken into account when evaluating the efficiency of companies active in the transport sector. This was realized by $\mathrm{Yu}$ and Lin who created a novel variant of DEA, network data envelopment analysis (NDEA) or also referred to as multi-activity network data envelopment analysis (MNDEA). Although this technique is not very widespread yet, it is still worth mentioning, as it can provide deeper insights into the efficiency characteristics of the transport companies.
The method applied by Yu and Lin [30] introduces some specific changes to the traditional DEA method, hence enabling a novel approach to the efficiency evaluation of transport companies, in this case, railway companies. The idea behind the MNDEA model is that transport companies create multiple outputs from multiple inputs which should not be treated in an aggregated way as this would blur the results of efficiency evaluations. So Yu and Lin introduce a new model that handles freight transport and passenger transport on railways separately and establishes technical efficiency for these two individually. Having calculated technical efficiency, service effectiveness is determined by taking into account the data of consumption, i.e. the load factors achieved by the different railway companies. In this way the specific feature of transport production - that the consumption of the goods created is strongly interrelated with the date and time of their production, and thus they cannot be stored - can be taken into account in this MNDEA approach. The resulting model is applied to 20 European railway companies and it is not only their efficiency that is determined, but the areas of inefficiency (e.g. passenger or freight transport) are also identified. Yu [29] then applies MNDEA again to the railway sector, while $\mathrm{Yu}$ [31] shows an example of its application to the airports.

\section{Conclusion}

Having reviewed the international literature on the variants and applications of DEA in the transport sector, it has become clear how a scientifically well-founded research work is to be carried out in the field of efficiency evaluation with data envelopment analysis. After determining the scope of research and selecting the desirable inputs and outputs (keeping in mind the possibility of reducing them to principal components with PCA), the first step is obviously to collect the necessary amount of data. With premeditations about the nature of production characteristics of the DMUs, the DEA CCR or BCC method has to be chosen. In case of doubt, both techniques have to be applied, and the results obtained will show clearly, whether the production features constant or variable returns to scale. The results regarding the returns to scale can also be crosschecked with the Simar-Wilson method, which should by all means be utilized for determining the confidence intervals of the efficiency estimates, and the bias-corrected estimates. If a full rank of the efficiency values is needed, the super-efficient DEA model will come in handy, and in case of transport companies, the application of MNDEA can provide deeper insights into the components of efficiency. As DEA is a mathematically well-founded technique with a large number of international examples of its application, there is no reason why its merits should not be profited of in the Hungarian transport sector. Thus, further research can be directed towards its utilization in Eastern Europe, and within that, in Hungary. 


\section{References}

1 Adler N, Berechman J, Measuring airport quality from the airlines' viewpoint: an application of data envelopment analysis, Transport Policy 8 (2001), 171-181, DOI 10.1016/S0967-070X(01)00011-7.

2 Adler N, Golany B, Evaluation of deregulated airline networks using data envelopment analysis combined with principal component analysis with an application to Western Europe, European Journal of Operational Research 132 (2001), 18-31, DOI 10.1016/S0377-2217(00)00150-8.

3 Andersen A, Petersen C N, A procedure for ranking efficient units in DEA, Management Science 39 (1993), 1261-1264, DOI 10.1234/12345678.

4 Banker R, Charnes A, Cooper W W, Some models for estimating technical and scale efficiencies in data envelopment analysis, Management Science $\mathbf{3 0}$ (1984), 1078-1092, DOI 10.1287/mnsc.30.9.1078.

5 Barros C P, Airports in Argentina: Technical efficiency in the context of an economic crisis, Journal of Air Transport Management 14 (2008), 315-319, DOI 10.1016/j.jairtraman.2008.08.005.

6 Barros C P, Peypoch N, An evaluation of European airlines' operational performance, Int. J. Production Economics 122 (2009), 525-533, DOI 10.1016/j.ijpe.2009.04.016

7 Barros CP, Dieke P U C, Measuring the economic efficiency of airports: A Simar-Wilson methodology analysis, Transportation Research Part E 44 (2008), 1039-1051, DOI 10.1016/j.tre.2008.01.001.

8 Bazargan M, Vasigh B, Size versus efficiency: a case study of US commercial airports, Journal of Air Transport Management 9 (2003), 187-193, DOI 10.1016/S0969-6997(02)00084-4.

9 Bokor Z, Elaborating Cost and Performance Management Methods in Transport, Promet - Traffic\&Transportation 21 (2009), no. 3, 217-224.

10 Bunkoczi L, Pitlik L, Possibilities of applying the DEA method for the measurement of factory efficiency, Agrárinformatika (1999), 313.

11 Charnes A, Cooper W W, Rhodes E, Measuring the efficiency of decision making units, European Journal of Operational Research 2 (1978), 429-444.

12 Coelli T J, A Guide to DEAP Version 2.1: A Data Envelopment Analysis (Computer) Program Centre for Efficiency and Productivity Analysis (CEPA), The University of New England, Armidale, Australia, 1996. Working Papers.

13 Cooper W W, Seiford L M, Zhu J, Handbook on Data Envelopment Analysis, Kluwer Academic Publishers, UK, 2004.

14 Cullinane $\mathbf{K}$, Ji $\mathbf{P}$, Wang $\mathbf{T}$, The relationship between privatization and DEA estimates of efficiency in the container port industry, Journal of Economics and Business 57 (2005), 433-462, DOI 10.1016/j.jeconbus.2005.02.007.

15 Farrel M J, The measurement of productive efficiency, Journal of Royal Statistical Society A 120 (1957), 253-281.

16 Hirschhausen C V, Cullmann A, A nonparametric efficiency analysis of German public transport companies, Transportation Research Part E 46 (2010), 436-445, DOI 10.1016/j.tre.2009.11.005.

17 Hung S W, Lu W M, Wang TP, Benchmarking the operating efficiency of Asia container ports, European Journal of Operational Research 203 (2010), 706-713, DOI 10.1016/j.ejor.2009.09.005.

18 Jitsuzumi T, Nakamura A, Causes of inefficiency in Japanese Railways Application of DEA for managers and policymakers, Socio-Economic Planning Sciences 44 (2010), 161-173, DOI 10.1016/j.seps.2009.12.002.

19 Markovits-Somogyi R, Measuring efficiency in transport: The state of the art of the application of data envelopment analysis, Transport 26 (2011), no. 1, 11-19, DOI 10.3846/16484142.2011.555500.

20 Martin J C, Roman C, An application of DEA to measure the efficiency of Spanish airports prior to privatization, Journal of Air Transport Management 7 (2001), 149-157, DOI 10.1016/S0969-6997(00)00044-2.

21 Odeck J, How efficient and productive are road toll companies? Evidence from Norway, Transport Policy 15 (2008), 232-241, DOI 10.1016/j.tranpol.2008.05.002.

22 Pacheco R R, Fernandes E, Managerial efficiency of Brazilian airports,
Transportation Research Part A 37 (2003), 667-680, DOI 10.1016/S09658564(03)00013-2.

23 Pina V, Torres L, Analysis of the efficiency of local government services delivery. An application to urban public transport, Transportation Research Part A 35 (2001), 929-944, DOI 10.1016/S0965-8564(00)00033-1.

24 Sampaio R S, Neto O L, Sampaio Y, Efficiency analysis of public transport systems: Lessons for institutional planning, Transportation Research Part A 42 (2008), 445-454, DOI 10.1016/j.tra.2008.01.006.

25 Simar L, Wilson P, Nonparametric tests of returns to scale, European Journal of Operational Research 139 (2002), 115-132, DOI 10.1016/S03772217(01)00167-9.

26 Tibenszkyné Fórika K., Possibilities and conditions of efficiency measurement of the military higher education from an IT point of view, Zrínyi Miklós National Defence University, Bolyai János Department of Defence Technology, 2008. (in Hungarian) PhD. Thesis.

27 Wu Y C J, Goh M, Container port efficiency in emerging and more advanced countries, Transportation Research Part E 40 (2010), 1030-1042, DOI 10.1016/j.tre.2010.01.002.

28 Yoshida Y, Fujimoto $\mathbf{H}$, Japanese-airport benchmarking with the DEA and endogenous weight TFP methods: testing the criticism of overinvestment in Japanese regional airports, Transportation Research Part E 40 (2004), 533 546, DOI 10.1016/j.tre.2004.08.003.

29 Yu M M, Assessing the technical efficiency, service effectiveness, and technical effectiveness of the world's railways through NDEA analysis, Transportation Research Part A 42 (2008), 1283-1294, DOI 10.1016/j.tra.2008.03.014.

30 Yu M M, Lin E T J, Efficiency and effectiveness in railway performance using a multi-activity network DEA model, Omega 36 (2008), 1005 - 1017, DOI 10.1016/j.omega.2007.06.003.

31 Yu M M, Assessment of airport performance using the SBM-NDEA model, Omega 38 (2010), no. 6, 440-452, DOI 10.1016/j.omega.2009.11.003. 